\title{
Guidance teachers' and support staff experience of working with pupils with mental health difficulties in two secondary schools: an IPA study
}

Marcia Stoll

Julia McLeod

This is an Accepted Manuscript of an article published by

Taylor \& Francis in British Journal of Guidance and Counselling on 30 June 2020, available online: http://www.tandfonline.com/10.1080/03069885.2020.1785391 


\title{
Guidance teachers' and support staff experience of working with pupils with mental health difficulties in two secondary schools: an IPA study
}

\author{
Marcia Stoll \\ Abertay University, Dundee, Scotland \\ Julia McLeod \\ Abertay University, Dundee, Scotland
}

\begin{abstract}
An increase in mental health difficulties in children and young people has resulted in teachers and schools being asked to act as frontline mental health professionals. Although previous research has investigated teacher involvement in the identification and management of mental health issues in pupils, little is known about the lived experience of such teachers and support staff engaged in these activities. The present study uses Interpretative Phenomenological Analysis to explore the experiences of guidance teachers and support staff working with pupils with mental health difficulties. Findings indicate that guidance teachers and support staff are emotionally affected by such activities and believe that the provision of an optimum mental health service for pupils with mental health difficulties requires more time, training, a whole-school approach and access to a school-based counselling service. This study has several implications for practice suggesting support, training, and the use of assessment tools and outcome measures could help staff become aware of the efficacy of their interventions, and pupils of their progress.
\end{abstract}

Keywords: counselling; IPA; mental health; qualitative; school; support staff; guidance teachers

\section{Introduction}

Research evidence shows increasing levels in mental health problems in children and young people (Kessler, Berglund, Demler, Jin, Merikangas, \& Walters, 2005) globally (World Health Organisation, 2003) and across the UK (Pitchforth, Fahy, Ford, Wolpert, Viner \& Hargreaves, 2018). With an estimated $20 \%$ of children and adolescents experiencing mental health problems in the form of behavioural and emotional difficulties (Atkinson \& Hornby, 2002; World Health Organisation, 2003) and $10 \%$ of these being clinically diagnosed with a mental health disorder requiring input from Child and Adolescent Mental Health Service (CAMHS) (Green, McGinnity, Meltzer, Ford \& Goodman, 2005), it stands to reason that $96 \%$ of teachers within the UK believe that they have come into contact with pupils experiencing mental health problems (NASUWT survey, 2018). Thus schoolbased management of pupil mental health is a salient topic within government, education and mental health arenas. Experiencing mental health issues in childhood and adolescence has been shown to lead to the disruption of learning, truancy, exclusion and the possibility of leaving school without obtaining any qualifications or realising their potential (Green et al., 2005). Such childhood difficulties can negatively impact quality of life (Hofstra \& Verhulst, 2000; Kim-Cohen, Caspi, Moffitt, Harrington, Milne, \& Poulton, 2003) and continue into adulthood in the form of mental health 
problems which can lead to the perpetuation of a cycle of mental health problems from one generation to the next (Landstedt \& Almquist, 2019). With children spending between 25-27 hours a week at school with teachers acting in loco parentis, the need to help children and adolescents experiencing mental health problems within the school system is crucial (Mental Health Foundation, 2018).

Most schools acknowledge their responsibility for being responsive to mental health problems (Headley \& Campbell, 2013). The Targeted Mental Health in Schools (TaMHS) programme report (Wolpert et al., 2011) found that what is actually being implemented on the ground in the UK, is a diverse range of interventions varying widely from school to school, encompassing governmentfunded as well as voluntary sector counselling initiatives such as Place2Be, parenting interventions and whole-school initiatives (Corboy \& McDonald, 2007; Hoover-Dempsey et al., 2005). Evidence exists for the efficacy of a wide variety of school-based mental health interventions (Schucksmith, Jones \& Summerbell, 2010; Wolpert et al., 2011; Weare \& Nind, 2011); however, the impact of embedded counselling (McLeod \& McLeod, 2015) provided by guidance teachers and support staff is often overlooked.

Although teachers are crucial to the development and implementation of school-based mental health interventions and services (Franklin, Kim, Ryan, Kelly, \& Montgomery, 2012), many of them report that this aspect of their work can be stressful and difficult. In a UK-based study, Rothi, Leavey and Best (2008) interviewed 30 teachers, at all levels of seniority, from primary, secondary and special schools (pupil age range 3-18 years) about their responsibilities around identifying pupils with mental health problems, and their evaluation of their own training and skills in relation to this task. Rothi et al. (2008) found that these teachers felt inadequately prepared to manage pupils with mental health needs, describing themselves as often feeling unable to discern between mental health problems and emotional/behavioural difficulties. They were also concerned that the impact of unmet needs increased their burden, diminishing their job satisfaction and wellbeing, and that the inadequate support for children with problems affected the wellbeing and performance of all the pupils in their schools. Some highly challenging mental health issues have the potential to exacerbate these concerns. For example, while post-primary teachers and guidance counsellors' from four schools in areas of both high and low deprivation in Ireland described themselves as sensitive to the detection of self-harm in pupils, they felt underequipped to know how best to respond, and often felt worried and felt out of their depth in their interactions with pupils displaying such problems (Dowling \& Doyle, 2016). However, Wolpert et als (2011) UK wide study of both primary and secondary schools found that school staff identified their access to colleagues with mental health expertise within the school, whom they could consult, as a major factor in supporting their effectiveness in responding to the needs of pupils with mental health issues.

In this present study, we explore the experiences of school staff tasked with providing pastoral care and support to pupils with mental health difficulties. The aim is to help them to identify their specific needs while carrying out this role, to enable them to provide better mental health care to their pupils. In order to highlight the distinctive frontline experience of guidance teachers and support staff, the study was carried out in in a city where the schools did not employ counsellors. Instead, young people with mental health issues could be referred for counselling to community mental health services (e.g. CAMHS) or a charity funded counselling agency such as Insight Counselling. School staff also signposted to free community-based youth agencies such as The Corner and Hot Chocolate Trust who also provide counselling services for young people. 


\section{Method}

A qualitative methodology, namely Interpretative Phenomenological Analysis (IPA) (Smith, Flowers and Larkin, 2009), was chosen in order to access lived experience. IPA studies focus on intensive exploration of the experience of a small number of participants, in order to be able to identify individual differences alongside general themes.

\section{Participants}

Participants came from two mixed-sex comprehensive secondary schools in Dundee, Scotland, UK and comprised members of the teaching or support staff directly involved in working with the pupils in a pastoral care capacity (where they are responsible for the welfare of their pupils, by providing holistic care, advice and personal support) for a minimum of five years, and who had experience of helping pupils with mental health problems. Participants included three guidance teachers, one support-for-learning teacher, a community school worker and a pupil support worker. Four of the participants had voluntarily sought varying levels of counselling training to help them cope better with the requirements of their role, and the remaining two participants had basic mental health training and were hoping to have some counselling training in the future. Five of the participants were female and one was male. All identified their ethnicity as white Scottish, with ages ranging from 29 to 51. Throughout this paper, participants are referred to as P1, P2 etc.

\section{Procedures}

After an informal discussion with teachers from several Dundee secondary schools, contact was made with the Head of Education from Dundee City Council and permission was given to contact the Head Teachers of two secondary schools in Dundee that had indicated an interest in participating in the study. Potential research participants were identified through consultation with a Deputy Head Teacher in one school, and the Head of Support for Learning in the other school. An overview of the study was provided to the guidance team and support for learning team in each school. Although the response rate was high, due to staff time constraints, it was agreed that only three staff members from each school would be interviewed. The participants then self-selected, and were invited to take part in two interviews, which were conducted a few months apart. Prior to the interview, participants received an information sheet, consent form, and interview schedule. The first interview consisted of an exploration of their perceptions of managing pupil mental health. The second interview allowed us to explore specific themes such as 'the emotional impact of doing this role' 'time constraints' and 'possible new solutions' in more detail, inviting them to share any further reflections that had occurred in the wake of the first interview, while ensuring the participants had been properly understood and their perspective had been appropriately expressed. Open-ended questions ('what kind of problems do your pupils come to you with?' and 'What do you do to help them?'), based on previous research (Green et al., 2005; Rothi et al., 2008) were developed to encourage participants to talk at length and expand on their experiences of identifying, understanding and helping their pupils with mental health problems, with minimal prompting from us as researchers. Interviews were audio-recorded and lasted between 40 and 120 minutes. Three of the second rounds of interviews were conducted face to face with the remaining three sent questions by email (due to a shortage of time and conflicting schedules). Approval for the study was granted by the University of Abertay Research Ethics Committee and Dundee City Council. 


\section{Data analysis}

Data analysis was conducted using IPA (Smith et al., 2009). Interview transcripts were annotated with exploratory comments from which themes in the data were developed and grouped into superordinate themes. This form of analysis attempts to highlight connections between themes in the text rather than finding examples that fit a pre-existing theoretical model (Smith, 2004). Quotes from participants are provided so readers can assess the degree to which the analysis effectively privileges the perspective of the participant.

\section{The researchers}

This research is informed and underpinned by the personal values and professional beliefs of the principal investigator (first author), who had five years' experience as a counsellor, lecturer and support worker in the Further Education sector. Before undertaking this study, I (MS) had little prior knowledge of how these guidance teachers and support staff managed pupil mental health issues in their respective school. Throughout conducting this research, I (MS) continually reflected upon and scrutinised my role in the shaping of the data collection and analysis process. The second author is a lecturer in counselling and experienced qualitative researcher with no prior experience of practice or research in school settings.

\section{Results}

In the interviews, the guidance teachers/support staff described being approached by pupils with a wide range of mental health issues with which they had then become involved: abandonment, abuse, anxiety, bereavement, depression, self-harm, and bullying. They reported being approached before/after class, during break time/lunchtime, in the corridor and after school. Pupils were also identified as at risk or a priority in staff weekly meetings, with systems or referrals to external agencies being put in place to support them. They indicated that the younger pupils (aged 12-15) in years 1- 4 tended to seek help for bereavement, bullying and relationship/falling out issues, and the senior pupils (aged 16-18) in 5th and 6th year with anxiety, depression and self-harm. It was also suggested that female students were most likely to seek help, and male students were most likely to get help once they had misbehaved in class and been sent to see their guidance teacher or support staff member. These conversations were usually ad hoc, and staff were frustrated as they could not arrange follow-up conversations with the pupils due to time pressures discussed as follows. As no supervision was available, guidance teachers/support staff stated that they sought support from colleagues when they could. Analysis of the interview transcripts identified three overarching themes alongside a number of linked subthemes (see Table 1). 
Table. 1 Overarching themes and sub-themes

\begin{tabular}{|c|c|}
\hline Theme & Subtheme \\
\hline The personal emotional impact of the work & $\begin{array}{c}\text { Taking it home } \\
\text { (All Participants) }\end{array}$ \\
The struggle to be helpful \\
\hline Awareness of time pressures & $\begin{array}{c}\text { School-based challenges } \\
\text { Multiple roles } \\
\text { (All Participants) }\end{array}$ \\
Strategic dilemmas \\
\hline Openness to new solutions & Whole-based approach \\
(All Participants) & School-based counselling \\
\hline
\end{tabular}

All six of the participants' data contributed to the three overarching themes. $\mathrm{P}$ and their number indicate which subthemes their data contributed to.

\section{Theme 1. The personal emotional impact of the work}

All six guidance teachers/support staff reported that they had been emotionally affected by their experiences of trying to help pupils with mental health problems. This broad superordinate theme incorporated a set of subthemes.

\section{Taking it home}

The subtheme of 'taking it home' emerged in the transcripts of four participants (P2, P4, P5 \& P6). Their apparent emotional responses indicated they experienced high levels of anxiety and fear regarding their pupils' mental health, and experienced anxiety regarding their ability to provide the help they felt was needed. They expressed that they took these feelings home with them, highlighting a negative impact on their wellbeing associated with their experience of helping pupils with mental health problems. Examples of such responses included:

"I was so alarmed about the mental health of this young person that (pause), I will take your phone number home, and I was fearful, well I was fearful, yesterday that in fact I still haven't seen her ... I am very reluctant to give out my mobile number but when you have that state of, when there's a crisis how I could not be there ... (P4)."

"... and I would think about her and be so traumatised I would go home and cry (P2)."

"It is difficult not to get hung up in what you're doing or taking it home ... It would be good to have someone to offload to (P6)."

Participants 2 and 4 seemed to be the most negatively emotionally affected due to their experiences of helping pupils with mental health problems, resulting in a sense of helplessness about their lack of ability to support them and lack of power to change their pupils' situations. Participant 5 sounded upset at this point during the interview and used the term 'sad' while explaining about not always having the time to listen/talk to pupils with mental health problems. This participant was also left 
worrying about these pupils and the impact this could have on them. They wondered if this might deter these pupils from seeking them out again or make them think they did not matter.

\title{
Using counselling skills
}

All participants talked in ways that expressed an acknowledgment and understanding of using counselling skills as part of their professional role and expressed how they were personally being affected by carrying out this role. The use of such skills provided a framework within which emotional aspects of this area of their work could be understood and managed, as well as leading to increased awareness of the personal, organisational and training implications of this aspect of their work.

\begin{abstract}
"There's a danger of people saying you're experienced in something that you're not ... and I worry about this ... we have to be careful, we say 'we do not offer counselling but use counselling skills' (P3)."

"On one hand it's almost like a counselling based service. Pupils will drop in and we'll discuss their issues ... I follow Egan's idea, the skilled helper model gives me structure ... but I do worry that this can only take me so far, and recognise that I only feel confident working with pupils I perceive as less severe requiring smaller low level interventions (P5)."

"I was definitely using counselling skills... it was finding the right balance between showing them myself, and the empathic response... After my training I feel quite confident when I get to have helping conversations with them, that I'm saying the right things... Ideally I'd like for us to be free of our teaching commitments, get counselling training, and focus solely on providing pastoral support as there is definitely a need for it. It would take up all my time. But because of money they won't let us. But then they won't give us the counselling support either (P6)."
\end{abstract}

All the participants agreed that they used counselling skills to build relationships and have helpful conversations with their pupils while trying to help them manage their mental health. They also acknowledged that they had all been emotionally 'touched' (both positively and negatively) by their helping experience which had then influenced them to seek more training in this area.

\section{The struggle to be helpful}

The guidance teachers and support staff interviewed in this study worried about how effective they were in relation to their capacity to support young people with mental health problems. They all mentioned that having some sort of outcome measure would be helpful. Three participants felt confident in their abilities and their impact, while the other three described themselves as feeling that they did not have the specialist training required in order to adequately meet certain levels of their pupils' mental health difficulties. The experience of fluctuations in personal sense of selfefficacy represented an important element of the overall emotional demands of responding to pupil mental health issues.

“... it's not my area of expertise ... I'm not a counsellor, I'm not a psychologist, I'm a teacher (P5)." 
"I can't deliver I think, the support that certain young people need and I really struggle ... and I worry I can make it worse ... I do have a fear that we say the wrong thing I don't want to say the wrong thing, or be unable to identify where something is becoming more serious or more alarming because l've not picked up on triggers and other people are more expert than that (P4)."

"I am not a mental health specialist ... I worry I'll say the wrong thing ... I don't have the knowledge or the skills to encourage her to open up ... (P2)."

\section{Theme 2. Awareness of time pressures}

As previously mentioned, all six guidance teachers/support staff talked about their awareness and experiences of time pressures, but here more importantly, they explored the impact of their apparent lack of time while trying to support their pupils with mental health problems.

\section{School-based challenges}

A lack of time due to the structure of the school day was a major influential factor and captured the emerging school-based challenges experienced by all the participants. This highlighted their feelings of frustration and an underlying tension between fulfilling their roles and providing the level of support they would like to offer, resulting in them feeling like they are unable to get to the root of, or address underlying issues of their pupils with mental health problems. Here the guidance teachers and support staff stressed how they felt the diversity of the pupils' backgrounds and needs are influential factors on the types of problems they see, and which they do not always have time to address.

\footnotetext{
"I feel there are ... lots of pressures on my time (P5)."

"Time is our biggest barrier. We are limited to the amount of hours (pause) time we can spend with our pupils ... time is precious ... (P6)."

"Our school day ... is so condensed it's frenetic ... it doesn't allow anybody to really speak to a teacher, or go to a service ... there's a failing of how we operate our school support because time is not available (P4)."
}

All the participants seemed extremely frustrated when talking about their lack of time within the school day and upset that they were only able to offer a reactive service opposed to the proactive service they felt would be more beneficial for their pupils with mental health difficulties and would stop the escalation of their problems. There was also a sense that they felt somewhat dejected while talking about their lack of time to provide the support they felt their pupils with mental health difficulties needed, as if they felt this was a longstanding issue over which they had no control and that they did not foresee improving in the near future. 


\section{Multiple roles}

Another subtheme to emerge was the multiple roles of the participants (with the guidance staff having teaching, pastoral support, development, named person and child protection remits; and the support staff having increasing and evolving remits including transition and group work as well external liaison responsibilities) and specifically how this impacts their time and ability to help pupils with mental health problems. The challenge of balancing multiple roles was captured by one teacher who explained that:

"I hate when you're on the cusp of them opening up and then the bell rings and I have to say I'm sorry I have to go and teach ... I hate saying that to them ... I feel frustrated, it's very very difficult to then walk away (P5)."

For the guidance teachers who took part in the study, frustration arising from multiple roles seemed to have three dimensions. First, they felt that their time was tied up in meetings when they felt it would be more effective working with pupils. Second, although they felt management was supportive, and they had made their situation known to management, no progress was being made to allow them more time to focus on developing the service for the mental health of their pupils. Third, they felt they were not getting help from the school community as a whole, which they felt would improve the quality of the service, providing them with more resources to help more pupils, and allow them to free up some time to work proactively.

\section{Strategic dilemmas}

Guidance teachers/support staff indicated that due to a shortage of time in their scheduled weekly meetings, they were only able to focus on what they characterised as the 'high tariff' young people, which did not allow for time for all the pupils they were concerned about to be discussed. As a result, they experienced continual dilemmas around strategic decision making in terms of identifying priorities.

\footnotetext{
"We don't focus on seniors which is one of the limitations of our system ... we only work with the targeted ones ... my worry is we miss opportunities to help young people (P5)."

"We work with the high profile ... we don't have enough time to help everyone (P3)."

"It is a lot of rushing about, and I don't think my ... class are getting the best experience of me, or the subject, ehm and I don't think the kids that immediately present themselves as I come in the door, I don't think they're getting the best of me either (P6)."

"We have good referral systems to get support for the targeted ones, and to a counselling service, but the waiting lists are long, and then sometimes it's difficult getting them out of school for the appointments (P5)."
}

The guidance teachers and support staff who were interviewed seemed to be disappointed that they could not give their best. They were tired and felt guilty due to having to go from class, to appointments with pupils/staff, to meetings, and that it felt like they did not have much left to give in those specific moments, when they felt they should be or could be giving more. They all seemed passionate about taking on more of a 'counselling role' and responsibility for pupils' mental health, 
hoping this would enable their pupils to get the best service they could offer, but felt constrained by these strategic dilemmas.

\section{Theme 3. Openness to new solutions}

The third theme to emerge was openness to new solutions, reflected in the underlying themes of a whole-school approach and school-based counselling.

\section{Whole-school approach}

Guidance teachers/support staff expressed value in a whole-school approach to enable a more cohesive and consistent approach working across the school, as well as a way to increase access to existing pastoral support for more pupils and thus a way of providing better school services to pupils with mental health problems.

"I think as a conduit, we all work together ... should work together here ... (P4)."

"... And that the wellbeing of young people is not just the guidance team, it's everybody's job ... all staff should feel empowered to help ... that's why it needs to become a part of the wider school community, because we can't provide that level of service for the young people that they need (P5)."

All six participants wanted all school staff to take responsibility and an active role in managing pupils' mental health difficulties but indicated that they had encountered resistance/opposition from some teachers who felt that this was not their role.

\section{School-based counselling}

As school-based counselling services are not mandatory in Scotland, all six participants seemed to be open to and welcome the idea of school-based counselling. Each had an idea of what they would want from the counsellor, and what this service might look like. This varied depending on what they considered to be the needs of their pupils, and their own assessment of what they can and would still like to provide.

"We would welcome a counsellor coming in. We're not threatened or don't worry about people stepping on toes ... If we had a bereavement counsellor once a week, they'd be full (P3)."

"I can't offer that continuity of service that a school-based counsellor can. It's someone who is there primarily to support the young people. They know exactly when they will be taken, they know exactly how long the session's going to last for and they know as I said that that person can then meet up with them in 2 weeks' time, and they will be there (P5)." 
All the teachers and support staff seemed genuine when they reported that they felt a school-based counselling service would be beneficial for aiding them and their school in supporting and managing their pupils with mental health problems. All the participants wanted a professional who would have time to provide early interventions, consistent allocated time for follow-up conversations, and be there just for the young people; as well as there to offer the teachers/support staff advice, training and their own counselling when they felt it was required.

\section{Discussion}

The guidance teachers' and support staff's accounts within this study highlight the emotional effects they experienced while offering pastoral support and managing pupils with mental health problems. The results of the present study reinforce the conclusions of Headley and Campbell (2013) and suggest that school teachers are in a unique position to be able to identify mental health problems in their students and are now tasked with acting as the 'frontline mental health professionals' (Gott, 2003; Rothi \& Leavey, 2006). Also consistent with previous research conducted by Visser, Koot and Verhulst (1999), this study showed that some of the guidance teachers and support staff worried about correctly identifying pupils with mental health problems. In addition, their concern was that they might make the situation worse as they were not sure of the right things to say and felt the existence of significant time pressures further restricts their capacity to function effectively in this role. The results from this study also indicate that despite these concerns, and the sometimes negative impact on their own mental wellbeing, these guidance teachers and support staff do want to assume this additional pastoral support responsibility with three out of the six participants already feeling confident that they were having a positive effect on improving the mental health of their pupils.

As also noted by Hornby and Atkinsons' (2003) findings in their framework for promoting mental health in schools, in this current study too, it is clear that these guidance teachers and support staff want a whole-school approach, more training, advice and support to improve their confidence and skills to help them carry out this support effectively. An important theme introduced by all the participants in this study was their desire to have a counsellor or other form of support for themselves 'to offload to', as a means of helping them cope with the negative emotional and psychological effects of working with pupils with mental health problems. They also wanted more counselling training and knowledge of counselling outcome measures to be able to adequately deal with the range of their pupils' mental health problems, adding yet another facet to existing literature. It was clear that these guidance teachers' and support staff's awareness of time pressures seemed to be inter-related and underlying throughout all their experiences of working with and supporting pupils with mental health difficulties. Our study introduces more specifically their frustrations at how their lack of time impacted on their perceived ability to provide the level or depth of early interventions and consistent support, or to undertake the counselling training that they felt was necessary to meet the needs of their pupils with mental health problems.

Both schools were viewed by participants as having good referral systems and several experienced people internally and externally to provide a variety of interventions. However, collectively they still felt that these services were not enough to meet the needs of their pupils with mental health difficulties. This emphasises a gap in their current service provision which they have identified as not having the time, resources or sometimes training to be able to offer the early interventions they 
think are most needed. Another contribution to the literature is the finding that these three guidance teachers wish to devote their time solely to that post, taking on more of the pastoral responsibilities to meet this need and thus giving up their teaching responsibilities. They intimated that the current budget does not allow for this as replacement teachers would need to be hired to fill their role. It seems a more cost-effective and structural solution to propose a school-based counsellor who would have the time and training to provide those early interventions. They could also provide the appropriate advice, guidance and staff support that these teachers and support staff have stated that they want and need. In line with USA-based research (where school-based counselling is mandatory in several states) showing significant efficacy for school-based counselling interventions for pupils aged 5-18 (Baskin, Slaten, Corsby, Pufhal, Schneller \& Ladell, 2010), and similar to Cooper (2013); McArthur, Cooper and Berdondinis' (2013) findings in the UK showing the effectiveness of school-based counselling services in reducing psychological distress in young people, these guidance teachers and support staff felt school-based counselling would offer their pupils the time and appropriate level of care and mental health support that they felt was missing, and that they could not provide.

The ways in which these guidance teachers and support staff want assistance and support to enable them to provide their optimum level of pastoral support for their pupils with mental health difficulties has already been established. Time, counselling training and on-hand advice were the most sought after. As time is a commodity that is not readily or soon to be available, they displayed openness to new solutions which incorporated school-based counselling and adopting a wholeschool approach which they are currently trying to implement through government policy Getting it Right for Every Child (GIRFEC, 2008). The implications from this study are clear. However, the implementation of the support and training, along with a school-based counselling service and whole-school approach these guidance teachers and support staff felt they needed, is an issue that needs to be addressed by the government and local authorities.

\section{Limitations of the study}

The results need to be interpreted with caution and taken within the context of the methodological approach that was adopted. The findings offer only a brief and time-limited insight into the perceptions of a small cohort of guidance teachers and support staff within the specific context of their pastoral role. Participants were first identified by senior management as staff with particular interests and experience in pupil mental health, so it may be that teachers and support staff with less involvement in this area of work would have different attitudes and understandings. It is also possible that another interviewer, from a non-counselling professional background, might have elicited different responses. In addition, it needs to be emphasised that the study took place in a city in which school counselling has not been established, with the consequence that informants were not able to draw on first-hand experience of the advantages and limitations of that type of intervention.

\section{Conclusion}

The findings of this study show that guidance teachers and support staff are highly committed to ensuring that mental health needs of pupils are addressed, but are worried about the negative impact that insufficient or late interventions can have on their pupils' mental health difficulties, which in turn negatively affects their own wellbeing. Participants believed that a school-based counselling service and whole-school approach would be beneficial. The findings from this study can hopefully be used to inform future research and work-based practice for professionals working with pupils with mental health difficulties. 


\section{References}

Atkinson, M., \& Hornby, G. (2002). Mental health handbook for schools. London: Routledge Falmer.

Baskin, T. W., Slaten, C. D., Crosby, N. R., Pufahl, T., Schneller, C. L., \& Ladell, M. (2010). Efficacy of counseling and psychotherapy in schools: A meta-analytic review of treatment outcome studies 147. The Counseling Psychologist, 38(7), 878-903.

Cooper, M. (2013). School-based counselling in UK secondary schools: A review and critical evaluation. University of Strathclyde: Glasgow.

Corboy, D., \& McDonald, J. (2007). An evaluation of the CAST program using a conceptual model of school-based implementation. Australian e-Journal for the Advancement of Mental Health, 6(1), 6377.

Dowling, S., \& Doyle, L. (2016). Responding to self-harm in the school setting: the experience of guidance counsellors and teachers in Ireland. British Journal of Guidance \& Counselling. https://doi.org/10.1080/03069885.2016.1164297

EBPU, C. (2011). Me and My School: Findings from the National Evaluation of Targeted Mental Health in Schools (TaMHS) 2008-2011.

Franklin, C. G., Kim, J. S., Ryan, T. N., Kelly, M. S., \& Montgomery, K. L. (2012). Teacher involvement in school mental health interventions: A systematic review. Children and Youth Services Review, 34(5), 973-982.

Gott, J. (2003). The school: The front line of mental health development? Pastoral Care in Education, 21(4), 513.

Green, H., McGinnity, Á., Meltzer, H., Ford, T., \& Goodman, R. (2005). Mental health of children and young people in Great Britain, 2004. Basingstoke: Palgrave Macmillan.

Headley, C., \& Campbell, M. A. (2013). Teachers' Knowledge of Anxiety and Identification of Excessive Anxiety in Children. Australian Journal of Teacher Education, 38(5), n5.

Hofstra, M. B., \& Verhulst, F. C. (2000). Continuity and change of psychopathology from childhood into adulthood: a 14-year follow-up study. Journal of the American Academy of Child \& Adolescent Psychiatry, 39(7), 850-858.

Hornby, G., \& Atkinson, M. (2003). A framework for promoting mental health in school. Pastoral Care in Education, 21(2), 3-9.

Hoover Dempsey, K. V., Walker, J. M., Sandler, H. M., Whetsel, D., Green, C. L., Wilkins, A. S., \& Closson, K. (2005). Why do parents become involved? Research findings and implications. The Elementary School Journal, 106(2), 105-130.

Kessler, R. C., Berglund, P., Demler, O., Jin, R., Merikangas, K. R., \& Walters, E. E. (2005). Lifetime prevalence and age-of-onset distributions of DSM-IV disorders in the National Comorbidity Survey Replication. Archives of General Psychiatry, 62(6), 593-602.

Kim-Cohen, J., Caspi, A., Moffitt, T. E., Harrington, H., Milne, B. J., \& Poulton, R. (2003). Prior juvenile diagnoses in adults with mental disorder: Developmental follow-back of a prospective-longitudinal cohort. Archives of General Psychiatry, 60, 709-717. A 
Landstedt, E., \& Almquist, Y. B. (2019). Intergenerational patterns of mental health problems: the role of childhood peer status position. BMC psychiatry, 19(1), 286.

McArthur, K., Cooper, M., \& Berdondini, L. (2013). School-based humanistic counseling for psychological distress in young people: Pilot randomized controlled trial. Psychotherapy Research, 23(3), 355-365.

McLeod, J., \& McLeod, J. (2015). Research on embedded counselling: An emerging topic of potential importance for the future of counselling psychology. Counselling Psychology Quarterly, 28(1), 27-43.

Mental Health Foundation Scotland. (2018). Make It Count. Let's put health and wellbeing at the heart of Scotland's schools: Mental Health Foundation.

National Association of Schoolmasters Union of Women Teachers (NASUWT) (2018). Schools need support to deal with mental health upsurge among pupils. Retrieved October 32019 from https://www.nasuwt.org.uk/article-listing/bullying-harassment-and-mental-healthissues.html

Parliament, S. (2008). Getting it Right for Every Child. Edinburgh, Scottish Government, available online at www. scotland. gov. uk/Topics/People/Young-People/childrensservices/girfec.

Pitchforth, J., Fahy, K., Ford, T., Wolpert, M., Viner, R. M., \& Hargreaves, D. S. (2019). Mental health and well-being trends among children and young people in the UK, 1995-2014: analysis of repeated cross-sectional national health surveys. Psychological medicine, 49(8), 1275-1285.

Rothì, D. M., \& Leavey, G. (2006). Mental health help-seeking and young people: A review. Pastoral Care in Education, 24(3), 4-13.

Rothì, D. M., Leavey, G., \& Best, R. (2008). On the front-line: Teachers as active observers of pupils' mental health. Teaching and Teacher Education, 24(5), 1217-1231.

Scottish Government. (2008). Getting it right for every child (GIRFEC). A Guide to Getting it right for every child. https://www2.gov.scot/resource/doc/1141/0065063.pdf.

Shucksmith, J., Jones, S \& Summerbell, C. (2010) 'The role of parental involvement in school-based mental health interventions at primary (elementary) school level', Advances in School Mental Health Promotion, 3 (1), 18-29.

Smith, J. A., Flowers, P. \& Larkin, M. (2009) Interpretive Phenomenological Analysis: Theory, Method and Research. London: Sage.

Smith, J.A. (2004). Reflecting on the Development of Interpretative Phenomenological Analysis and its Contribution to Qualitative Research in Psychology. Qualitative Research in Psychology, Vol.1, 3954.

Visser, J. H., Koot, H. M., \& Verhulst, F. C. (1999). Continuity of psychopathology in youths referred to mental health services. Journal of the American Academy of Child \& Adolescent Psychiatry, 38(12), 1560-1568.

Weare, K., \& Nind, M. (2011). Mental health promotion and problem prevention in schools: what does the evidence say? Health promotion international, 26 (suppl 1), i29-i69.

Wolpert, M., Deighton, J., Patalay, P., Martin, A., Fitzgerald-Yau, N., Demir, E., \& Fugard, A. (2011). Me and My School: Findings from the National Evaluation of Targeted Mental Health in Schools 2008-2011. 
https://mc.manuscriptcentral.com/cbjg

World Health Organization. (2003). Caring for children and adolescents with mental disorders: Setting WHO directions. Geneva, World Health Organization. 